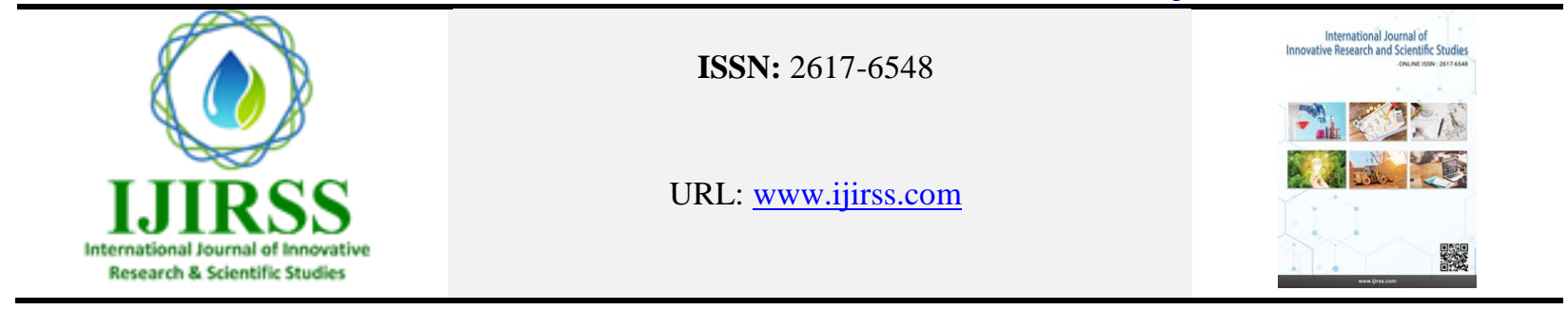

\title{
Evaluating the Percentage of Handicapped Individuals Using Media in Herat Province
}

\author{
Namatullah Sarwary \\ Faculty of Journalism, Herat University, Herat, Afghanistan \\ (Email:namatullah.sarwary123@gmail.com)
}

\begin{abstract}
Afghanistan is among the countries where majority of its people deal with tough circumstances. People with disabilities have more critical condition than others; they are deprived from many facilities and equipment, especially access to media. This research investigates the extent handicapped people use media and the impact of media on these people. By employing a qualitative method, data were collected from 21 disabled people through in-depth semi-structured interviews. The results demonstrated that a large number of handicapped individuals use media. The media which had been used among the handicapped individuals were radio, television, and magazines, whereas Radio was considered more practical. Media can have either positive or negative impacts on disabled people, but this impact differs among disabled people depending on their disabilities.
\end{abstract}

Keywords: Handicap, Media, Information.

DOI: 10.53894 /ijirss.v3i1.28

Funding: This study received no specific financial support.

History: Received: 1 January 2020/Revised: 20 January 2020/Accepted: 28 January 2020/Published: 3 February 2020

Licensed: This work is licensed under a Creative Commons Attribution 4.0 License $(\mathrm{coc}) \mathrm{Er}$

Competing Interests: The author declares that there are no conflicts of interests regarding the publication of this paper.

Transparency: The author confirms that the manuscript is an honest, accurate, and transparent account of the study was reported; that no vital features of the study have been omitted; and that any discrepancies from the study as planned have been explained.

Ethical: This study follows all ethical practices during writing. 
ارزيابى ميزان استفادة افراد داراى معلوليت از رسانه ها در ولايت هرات

\author{
نعمت الله سرورى \\ دانشكده زورناليزم، دانشعاه هرات، هرات، افغانستان
}

\title{
خلاصd
}

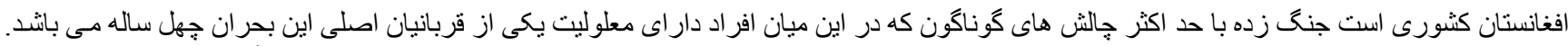

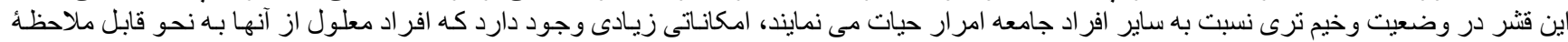

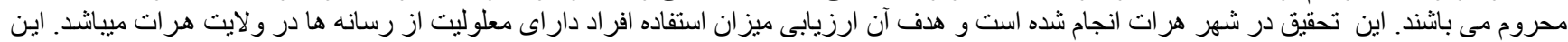

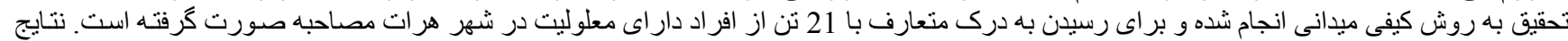

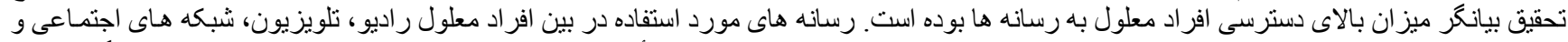

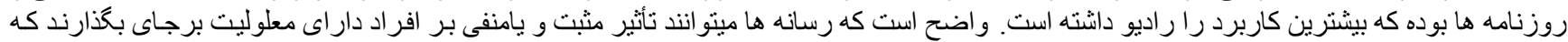

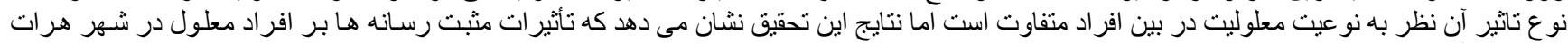
بيشتر از تأثثر ات منفى آن بوده است

كلمات كليلى : معلوليت، رسانه، اطلاعات

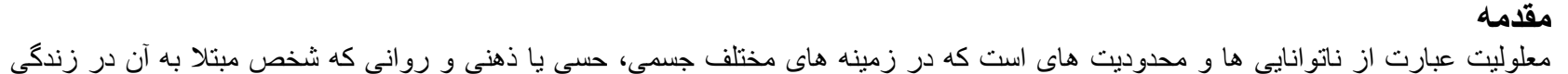

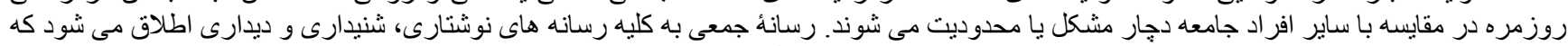

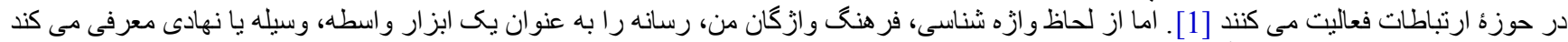

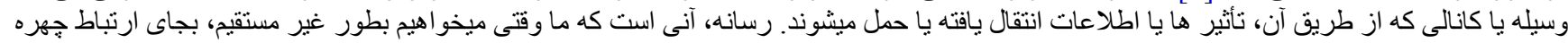

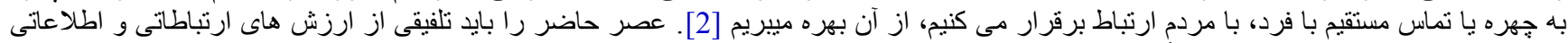

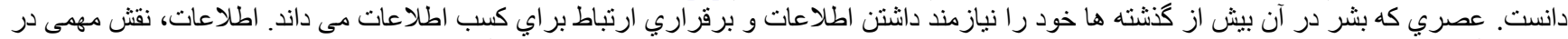

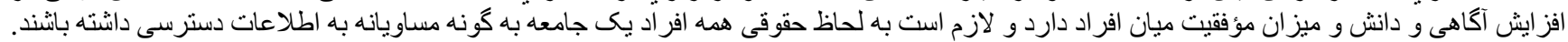

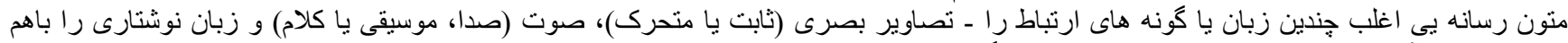

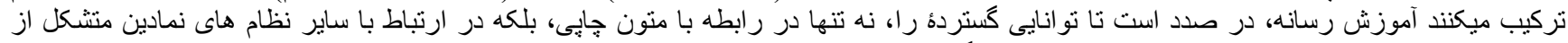

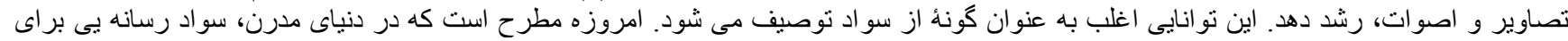

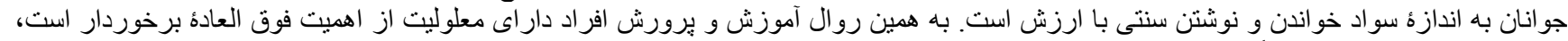

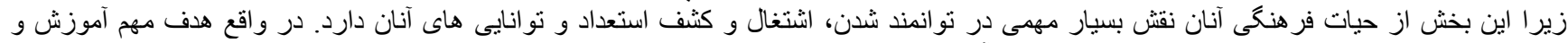

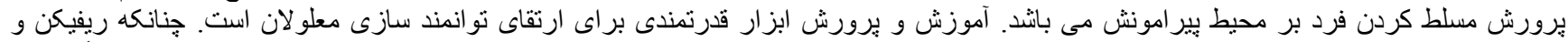

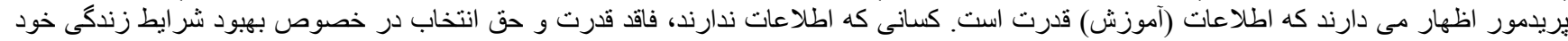

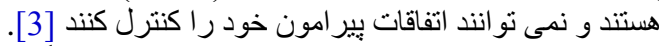

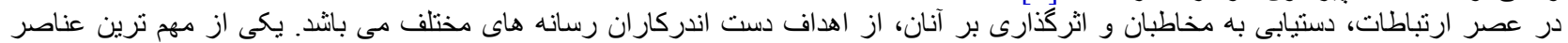

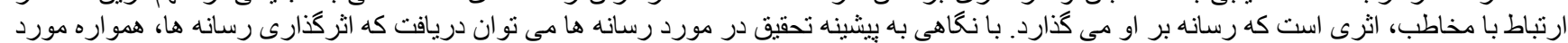

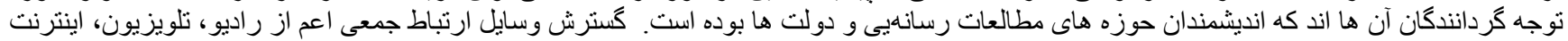

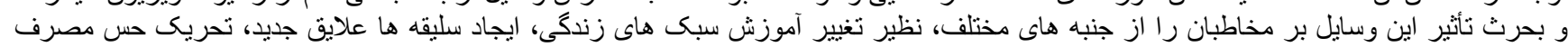

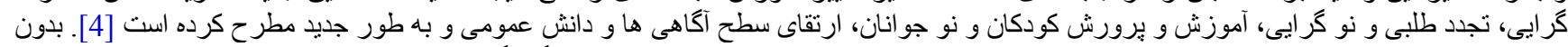

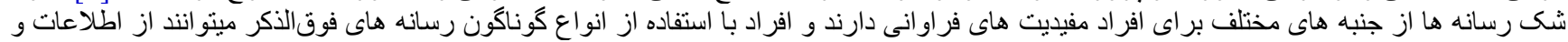

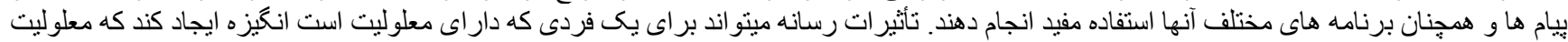

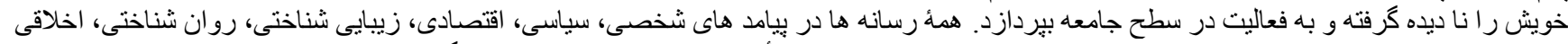

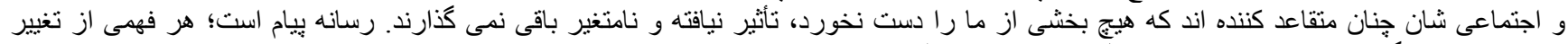

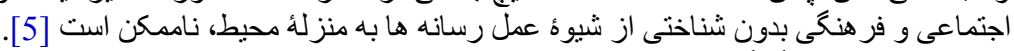

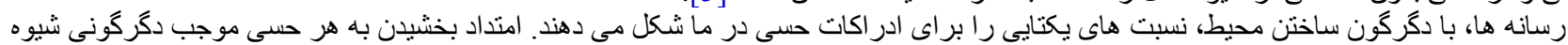

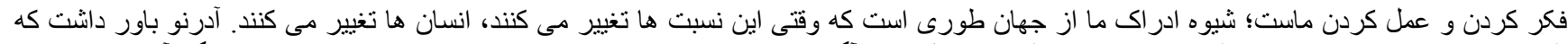

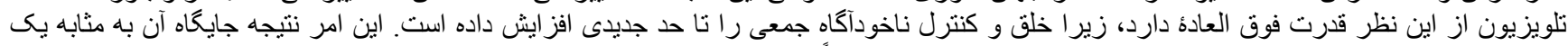

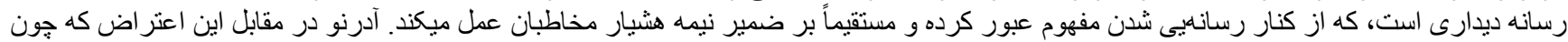

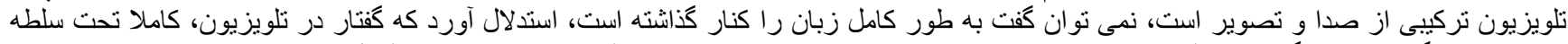

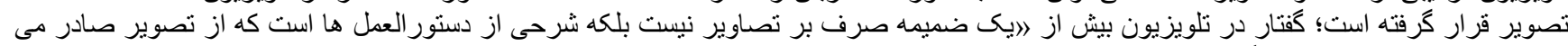

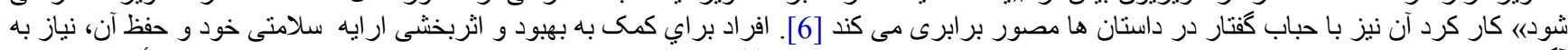

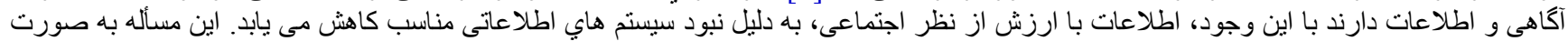

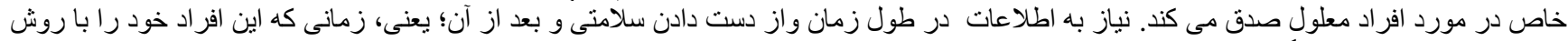

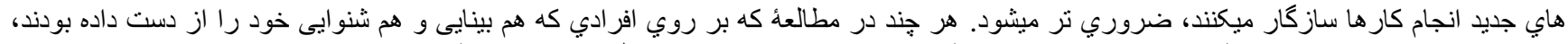

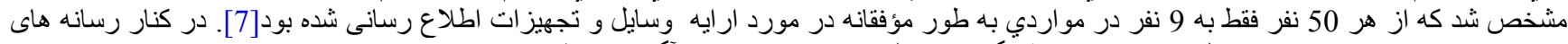

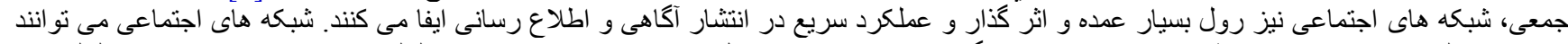

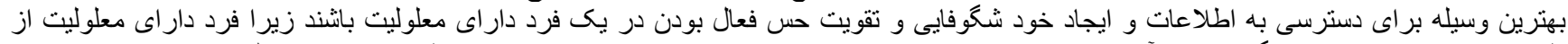

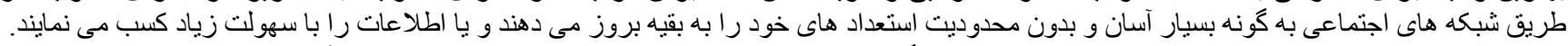

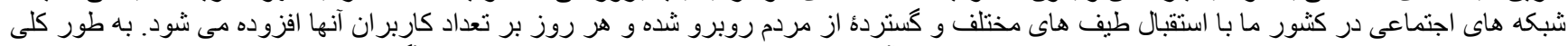

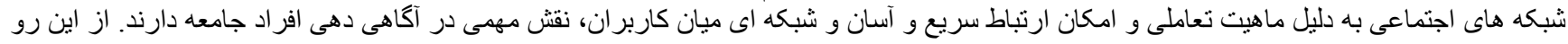




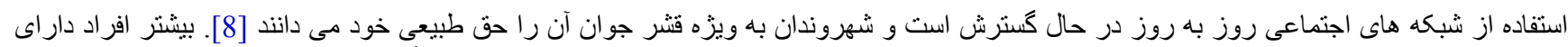

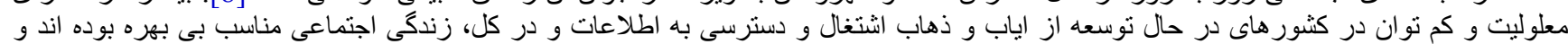

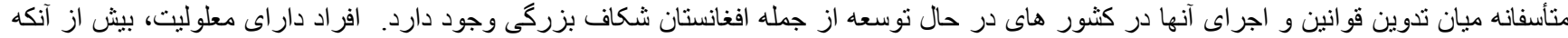

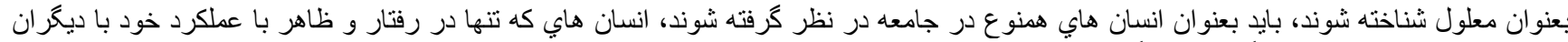

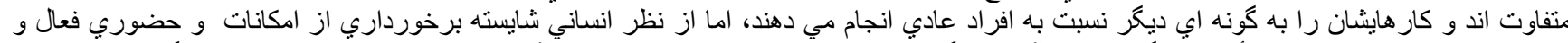

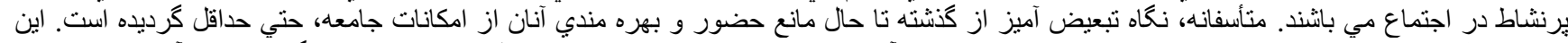

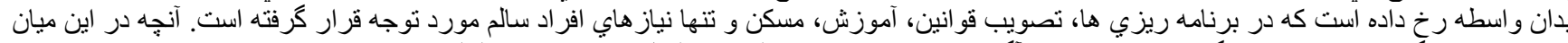

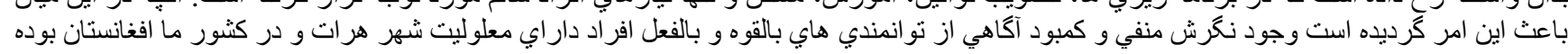

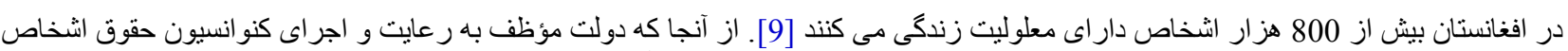

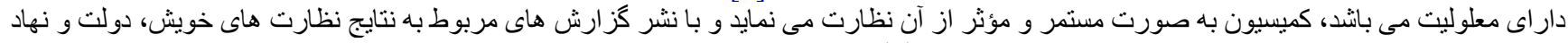

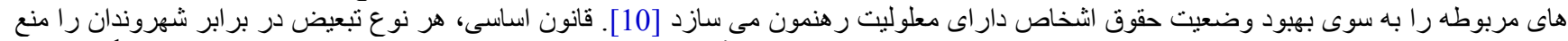

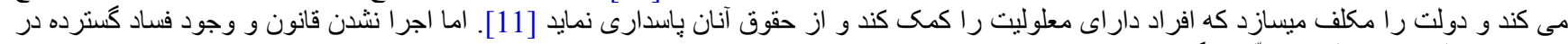

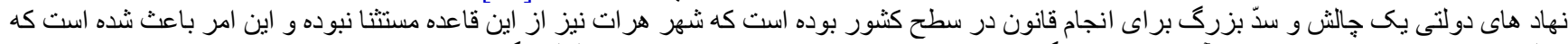

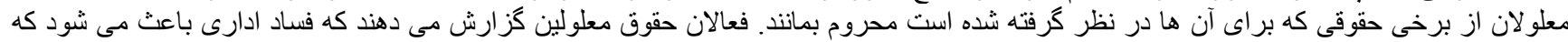

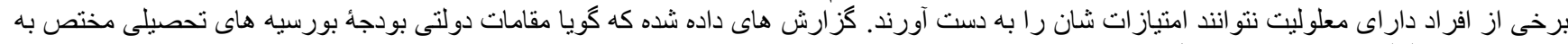

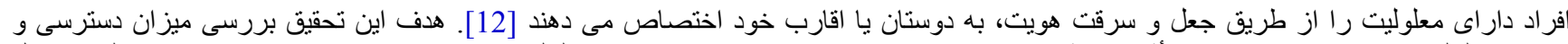

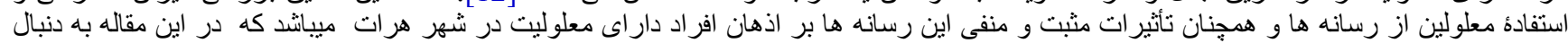

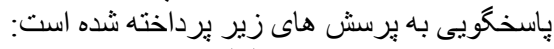

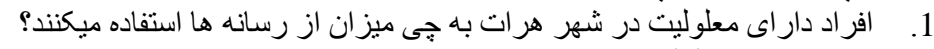

2.

3.

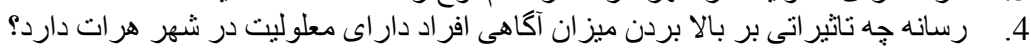

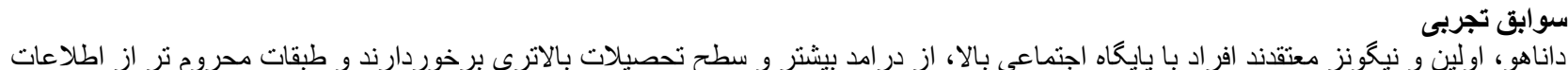

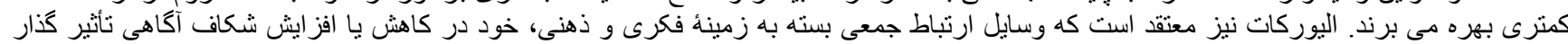

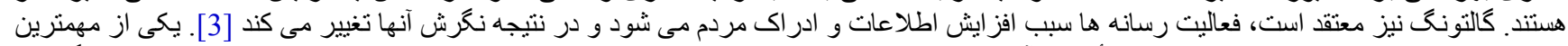

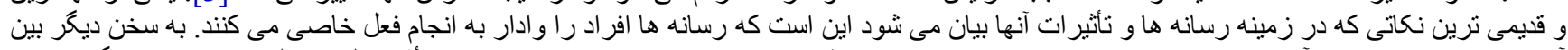

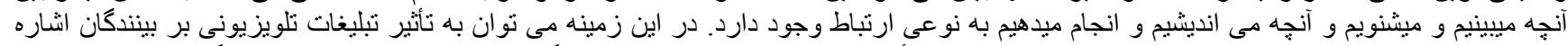

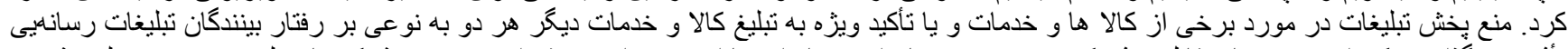

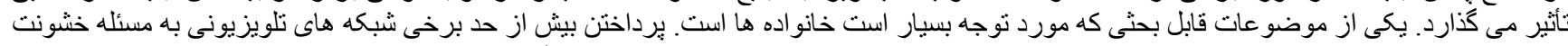

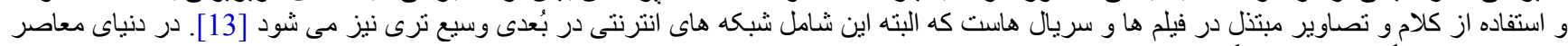

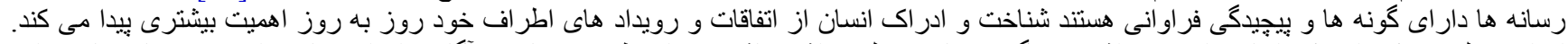

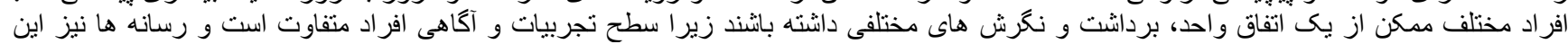

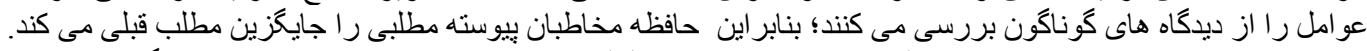

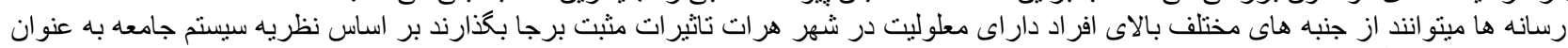

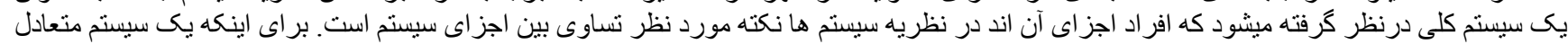

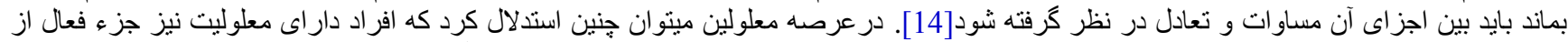

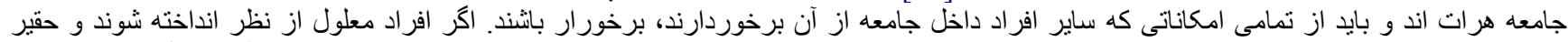

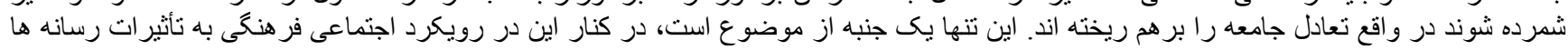

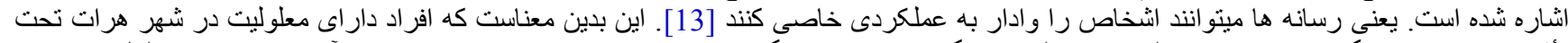

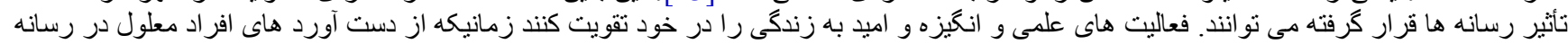

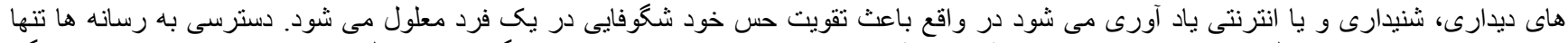

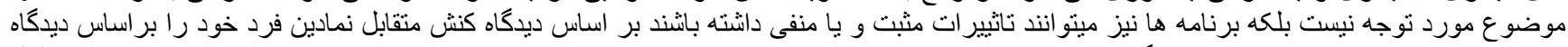

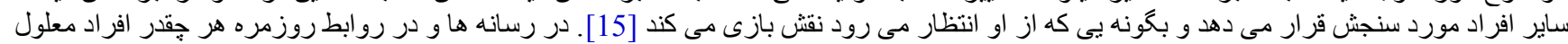

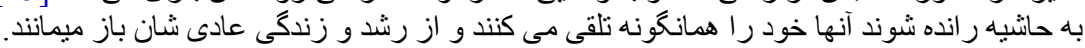

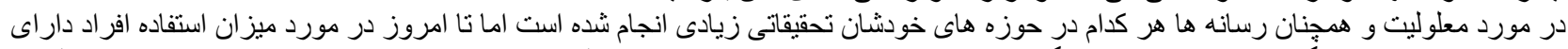

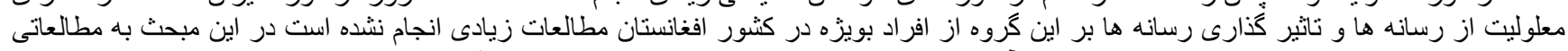

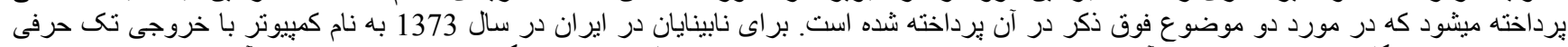

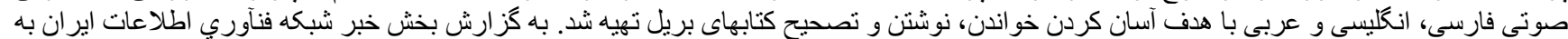

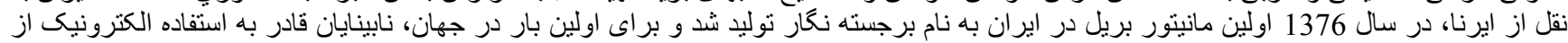

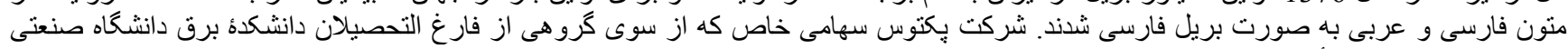

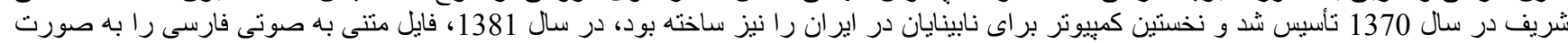

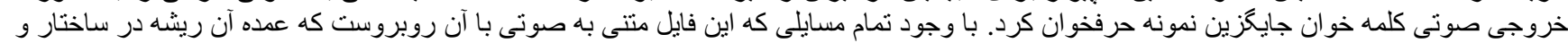

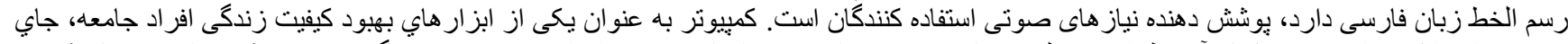

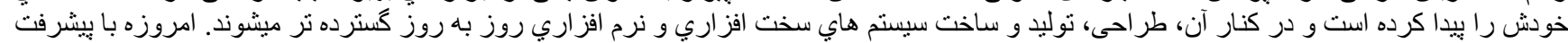

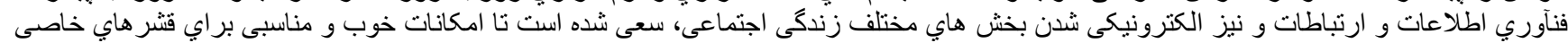

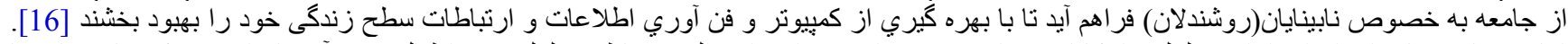

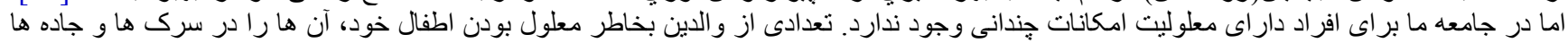

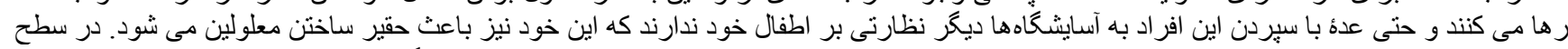

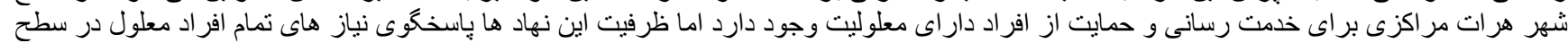

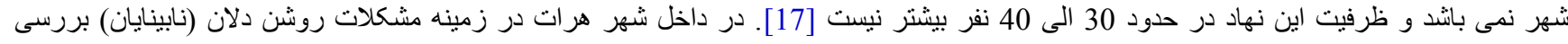




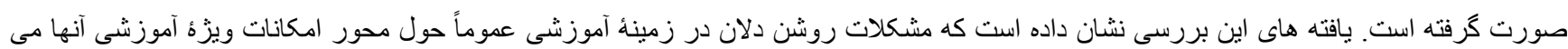

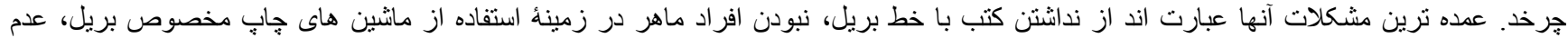

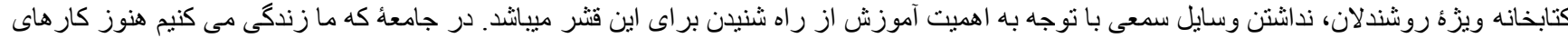

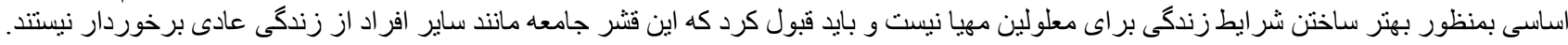

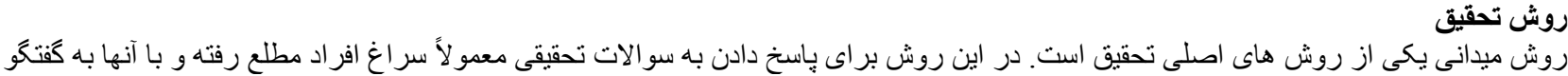

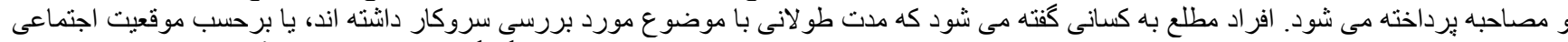

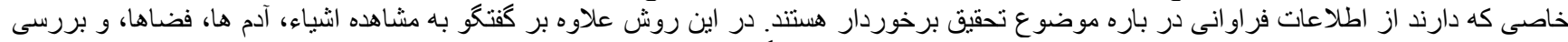

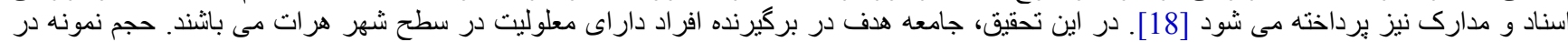

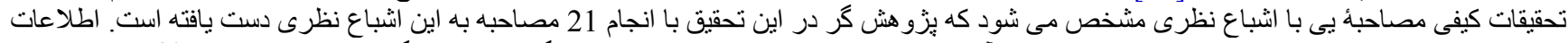

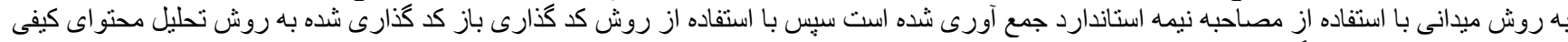
مورد تجزيه و تحليل قرار كرفتنه است.

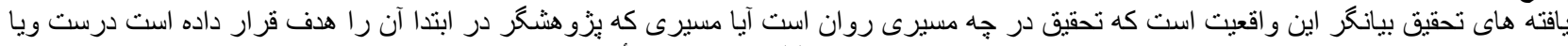

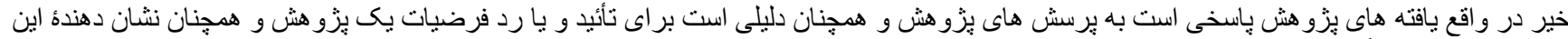

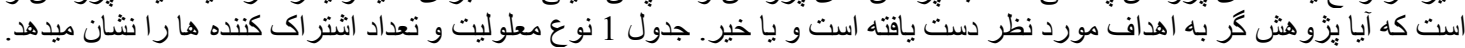

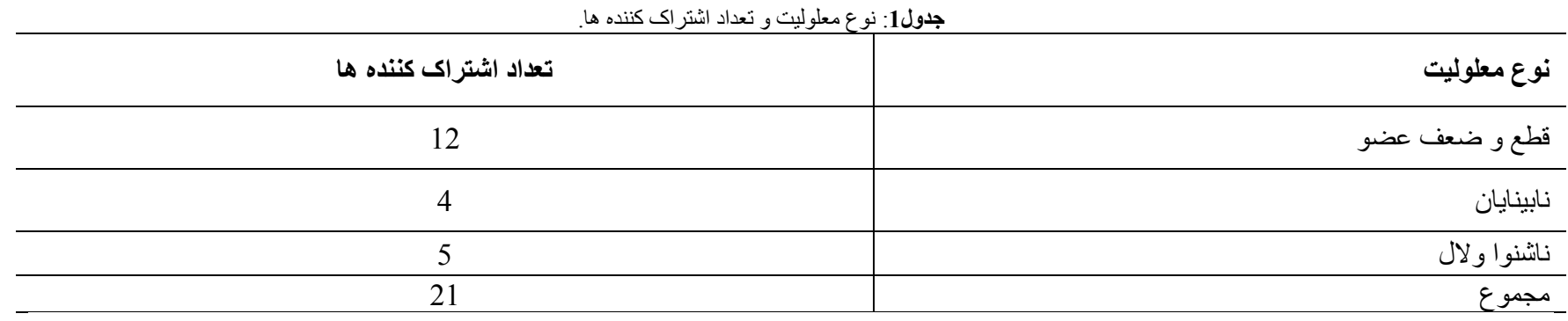

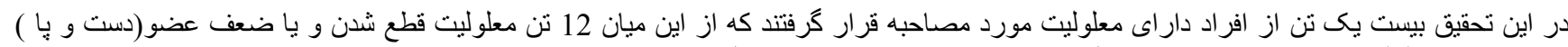

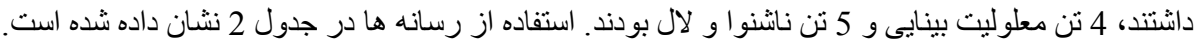

\begin{tabular}{|c|c|}
\hline تعداد اشتراك كنتنده هـا & باسخ اشتر اك كنتده ها \\
\hline 18 & بلى \\
\hline 3 & خير | خير \\
\hline 21 & مجموع مجمو \\
\hline
\end{tabular}

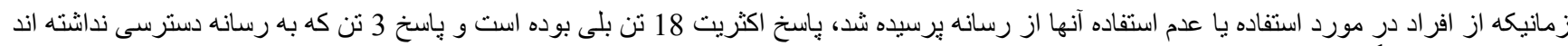

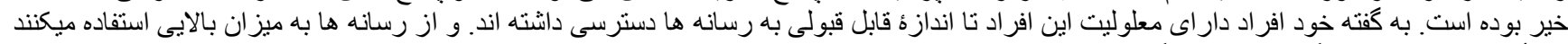

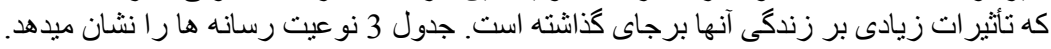

\begin{tabular}{|c|c|}
\hline & \\
\hline تعداد انشتراك كنتده ها & نوع رسائه \\
\hline 15 & راديو \\
\hline 11 & تلويزيون \\
\hline 13 & روزنامه و مجله \\
\hline 11 & شبكه هاى اجتماعى \\
\hline
\end{tabular}

\begin{tabular}{|c|c|}
\hline جنبه هاى منفى & جنبه هاى مثبت \\
\hline جلوه دادن معلوليت به عنوان ضعف & آكاهى از وضعيت كثور \\
\hline بـ بِرورش نا اميدى & برنامه هاى آموزشى \\
\hline ت تبليغات كاهش دهنده انكيزه & تفريح و سركرمى \\
\hline نبود برنامه هاي ويزه افر اد ناشنوا & افز ايش اعتماد به نفس \\
\hline ناديده كرفتن افر اد دار راى معلوليت در برنامه ها & انكيزه دهى \\
\hline- & زمينه رشد فكرى \\
\hline- & زمينه اظهار نظر \\
\hline- & زمينه خود شكو فايي \\
\hline
\end{tabular}

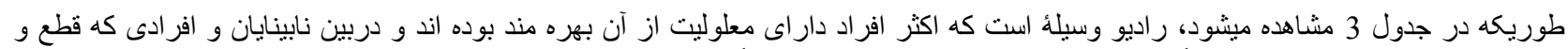

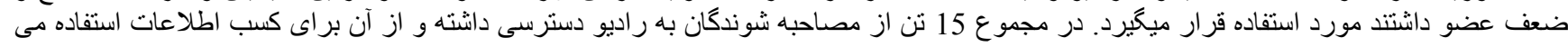




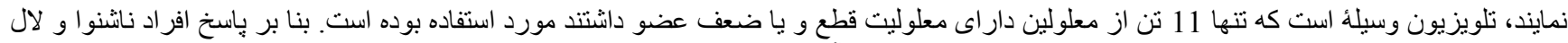

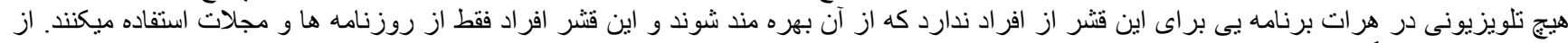

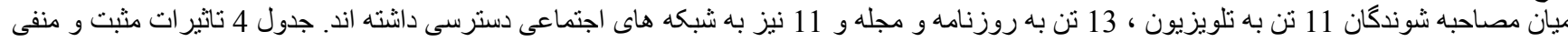
رسانه ها بالاى افر اد معلول مثان ميباشند.

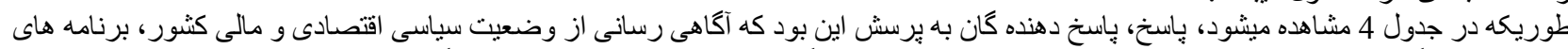

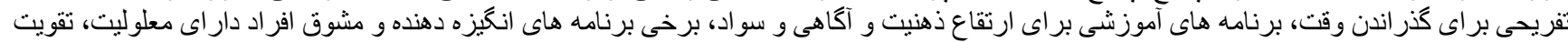

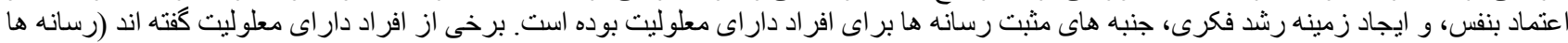

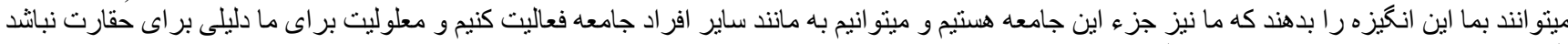

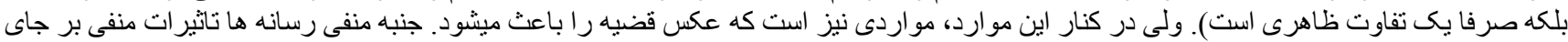

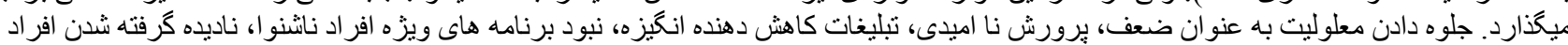

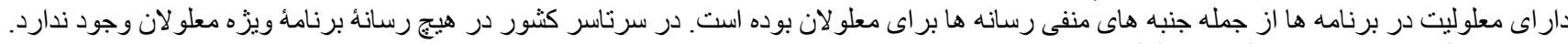

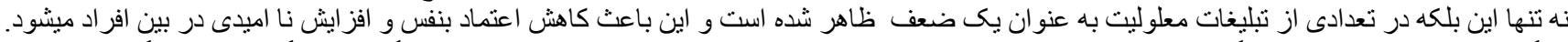

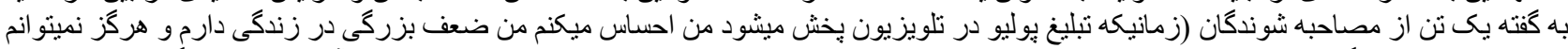

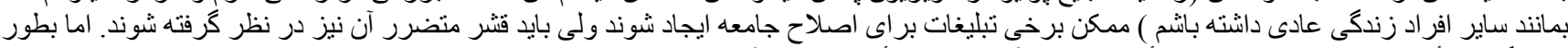

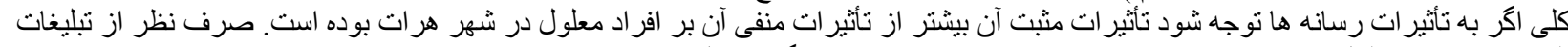

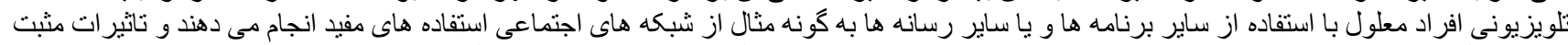

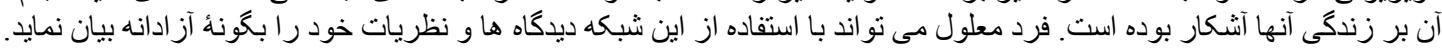

نتيجه كيرى و بيشنهادات

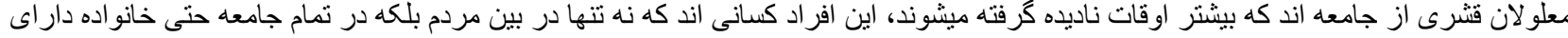

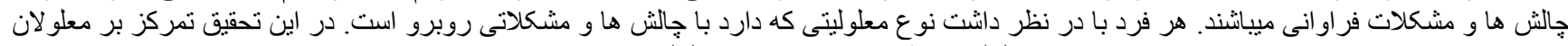

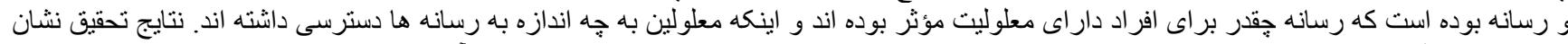

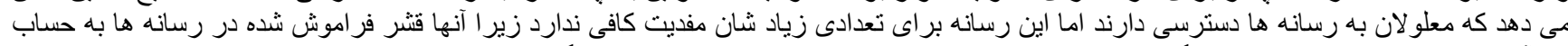

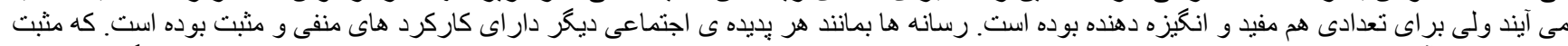

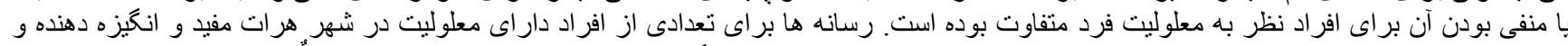

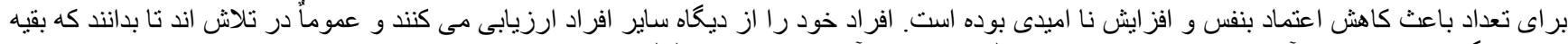

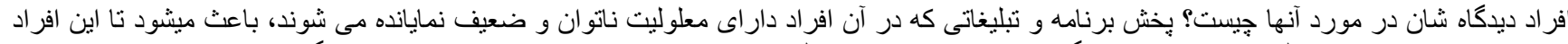

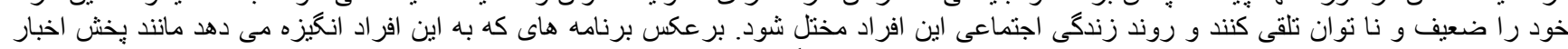

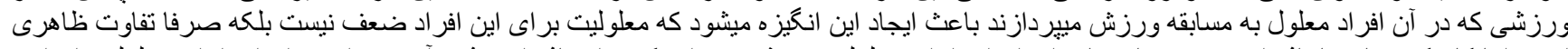

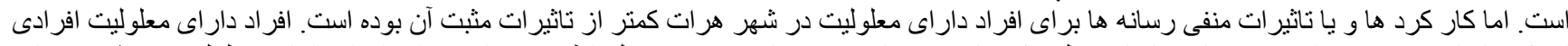

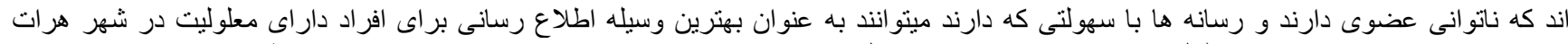

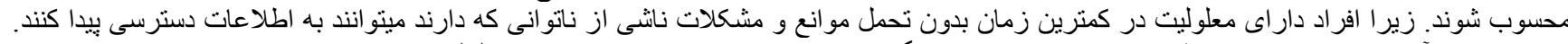

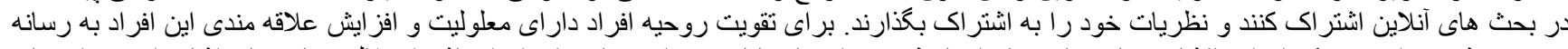

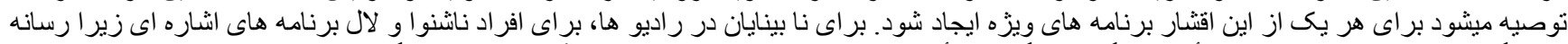

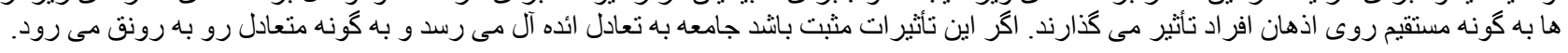

\section{References}

[1] N. Aghajani, N. Majidi, and J. Askari Kachusenko, "Investigating the role of Iranian sports media in promoting aport in aociety c," MNN Journal of Communication Culture, vol. 3, pp. 249-227, 2013.

[2] H. S. Buckingham and M. Roshani, Media education :Learning, media literacy and contemporary culture, 1st ed.: Publisher of Imam Sadegh (AS) University, 2010.

[3] S. Mohammadi and N. Nafchi, "Social and cultural factors affecting the admission of the disabled in the "Shahr-e Shahr Kurd"," Society pp. $107.2015,192-$

[4] A. Saadipour, F. Khoshgovian, and M. Talebi Dalir, "Effectiveness in the field of media with emphasis on television," Center for Research, Studies and Program Evaluation, p. 180, 2011.

[5] N. Amid and S. H. N. Ghaderi, Research in media - religion and media: University of Religions and Religions, 2009.

[6] J. Taylor and L. Harris, Critical theories of mass media (Past and Present) Translator: Yaghoub Nemati Vorojni: Publisher of Jam Jam Institute, 2010.

[7] S. C. Al Moore, "Advancing the rights of persons with disabilities. Retrieved from https://www.stimson.org/sites/default/files/file-attachments/Final_Farsi_1.pdf," p. 79, 2011. Strategies of Legal Awareness Communication, https://moj.gov.af/sites/default/files/dari_legal_awareness_strategy_0.pdf," p. 60, 2014.

[9] Inspiration, "Inspiration, protest of the disabled; Government inattention to 800 thousand disabled people. Retrieved from https://p.dw.com/p/RIw2," 2011.

[10] A. P. Hosseini, "Annual report on the activities and achievements of the fiscal Year 2015," Independent Human Rights Commission of Afghanistan, p. 68, 2015.

[11] Annual Report for Fiscal Year, "Afghanistan independent human rights commission. Retrieved from https://www.aihrc.org.af/home/annual_report ",7250/vol. 70, 1396.

[12] P. Saadati and A. F. Khalili, Community-based rehabilitation: World Health Organization, 2010.

[13] Tolouei, Media literacy: An introduction to learning and assessment. Center for Media Studies and Research, 2012.

[14] Boat, Communication and awareness (Concepts, Principles and Methods). Tehran: Soroush, 1396.

[15] N. B. Kamil, "Media theory (Sociology of Communication), Kavir," p. 328, 2009.

[16] F. N. Hassanzadeh and N. H. Fred, "A survey of the use of information and communication technology in iran for the blind to meet information needs," Information and Communication Technology in Educational Sciences, pp. 5-21, 2014.

[17] Specialty Monthly, "Publications of the council of specialists," 1396.

[18] A. A. Free, Professional research logic. Herat: Resalat, 1394. 